\title{
Tuberculosis and Gender in Nigeria, Sex Differences in Diagnosis and Treatment Outcome of TB and TB HIV Infected Patients
}

\author{
Article by Ejike Kenneth Nwene \\ Ph.D in Public Health, Texila American University, Nigeria \\ E-mail:ejike.ihv@gmail.com
}

\begin{abstract}
Background: Worldwide, gender differences are reported in diagnosis and treatment outcome of TB and TB HIV patients. Religious and socio-cultural factors are responsible but largely controversial. This study assessed gender issues in diagnosis and treatment outcome of TB and TB HIV patients.

Objective: To assess gender differences in diagnosis and treatment outcome of TB and TB HIV infected patients.

Methodology: We did a cross sectional retrospective analysis of 980 TB patients treated in 6 out of 21 randomly selected local government areas of Anambra state Nigeria between 2008 and 2012. Information on age, sex, HIV status, case notification, treatment outcome was evaluated from TB treatment cards and TB registers. Treatment outcome was recorded as cured, completed treatment, failed, defaulted, died.

Results: The male female ratio among the 980 TB patients was $57.4 \%$ vs $42.6 \%$.. The study HIV prevalence is $27.7 \%$; women contributed $52.6 \%$ of this population. Women had better treatment success rate than men $(85.7 \%$ vs. $80.5 \%)$. TB treatment outcome in women compared to men were Cured (50.4\% vs 40.7\%, $p=0.063$ ), treatment completed (35.3\% vs $39.8 \%, p=0.330$ ), died (5.5\% vs5.5\%, $p=0.8812)$, defaulter (6.55 vs10.5\%, $p=0.042$ ), failure $(1.6 \%$ vs $1.5 \%, p=0.749)$.

Conclusion: We conclude more TB cases in males but females are more prone to TB HIV confection, have better treatment outcome and lower default rate.

Gender-specific strategies, including active case finding among women, increased tracking and adherence for male, are warranted to optimize TB management.
\end{abstract}

Keywords: Gender, Nigeria, Tuberculosis, HIV, Co infection, NTBLCP.

\section{Introduction}

Tuberculosis (TB) remains a major global health problem in Nigeria. TB alongside human immunodeficiency virus (HIV) ranks as the leading cause of death from infectious disease worldwide and has surpassed HIV ${ }^{(1)}$. The situation is fuelled by increasing population density, poverty, demographic changes, immigration, weak political will, poor financial control management, inadequate human resources, weak health systems, poor laboratory services, drug-resistant TB; and lately by HIV AIDS pandemic ${ }^{(2,3)}$. All countries are affected by TB but $85 \%$ of cases occur in Africa (29\%) and Asia (56\%) ${ }^{(4)}$. Globally as at 2013, there were an estimated 9.0 million new TB cases and 1.5 million TB deaths (1.1 million among HIV-negative people and 0.4 million among HIV-positive people) ${ }^{(4)}$. The African region with approximately one quarter of the TB cases has the highest number of cases and death relative to population (280 incident cases per 100000 populations). Overall, 34\% of TB cases were estimated to be infected with HIV in African region (the highest) accounting for $78 \%$ of TB cases with HIV worldwide ${ }^{(4)}$. Nigeria is one of the 22 high burden countries that account for $80 \%$ of world TB cases. According to 2011 WHO estimate, Nigeria has estimated 320,000 cases of all forms of TB with yearly prevalence of 199 cases per 100,000 population and 210000 new cases representing an incidence rate of 133 per 100,000 population ${ }^{(5)}$. An estimated 250,000(150,000 - 350,000) TB death was recorded in Nigeria in $2013^{(4)}$. The 
Texila International Journal of Public Health

Volume 4, Issue 4, Dec 2016

current high number of TB death is unacceptable considering that TB is both preventable and treatable.

Over the years, we have had varying sex differences in different age groups and from different parts of the world for TB cases. The reasons for the sex differences are sometimes unclear ${ }^{(6)}$. Globally we have more males than females for TB case notifications and cases. In 2013, the male: female ratio in TB notification globally was 1.6, but among HBCs this ratio varied from 0.7 in Afghanistan to 2.9 in Viet Nam. ${ }^{(4)}$ Nigeria has a male: female ratio of 1.5. Variation among countries may reflect real differences in epidemiology as well as differential access to or use of health care services linked to the various TB programs. Various studies have shown that women lack of financial independence, low prioritization of women health by family members, gender specific stigma about TB are real barriers to treatment ${ }^{(7)}$. In some countries a woman with TB may be divorced if married or may find it hard to get married if unmarried while studies in Vietnam and Nepal found out that rejection, abandonment, ostracism, isolation followed TB diagnosis and leads them in some cases to traditional healers to reduce costs and stigma ${ }^{(8,9)}$. Other causes include barriers faced by women in accessing health care, repeated visits, travel costs, delays in test reports, rigid service timings, socioeconomic and cultural adversities and reduce poor women's ability to access services ${ }^{(6)}$. Despite all these factors women are less likely to default from the treatment as compared to men ${ }^{(10)}$. Even after adjusting for confounders the male sex was a strong risk factor of unsuccessful treatment outcome ${ }^{(11)}$.

Despite these findings showing increased male involvement and poorer TB treatment outcome, men are often overlooked in discussions of gender and TB. While global TB reports and meetings on gender acknowledge the fact that the majority of TB cases and TBassociated deaths occur among men, greater focus is usually placed on women. Globally, gender in most cases is referred to as women as exemplified by the Millennium Development Goals ${ }^{[12]}$. Subsequently, emphasis on TB involving men runs contrary to global norms ${ }^{[13]}$, and strategies to assess and address men's barriers to TB care are notably absent in researches globally.

Detailed literature research showed some limited research works from South East Nigeria examining gender-related differences in TB patients notified under the NTBLCP. The present study was designed to further help these other researches find out whether gender based differences are present in the notification rates, TB HIV co infection rate and treatment outcomes of TB patients registered under the NTBLCP in Anambra state in South East Nigeria to enable effective targeting of TB control strategies.

\section{Methodology}

\section{Study design}

This is a cross sectional retrospective study done to evaluate gender effects on diagnosis and treatment outcome of TB and TB HIV co infected patients in TB DOTS facilities in Anambra State.

\section{Study population}

The study population is all the TB patients that assessed treatment in the six chosen local governments using the DOTS therapy in Anambra State between the years 2004 - 2008. TB DOTS sites could be Stand Alone, Private, General, or Mission hospitals/clinics. All TB patients that got services through any health facility in the state that does not offer TB DOTS services were excluded. Anambra State is located in the South Eastern geopolitical zone of Nigeria made up of Anambra, Imo, Enugu, Abia and Ebonyi states. Anambra state has a very high density with a population of 4,182,032 individuals ${ }^{(14) .}$ and a land mass of 4844 square kilometer. Economically, Anambra state has a large urban population who occupationally are businessmen and traders. The rural areas of the state are mainly populated by farmers and petty traders. The state is made up of 21 local government areas (LGAs) all of which have existing TB DOTS facilities. The 21 LGAs are equally divided into three senatorial zones 
each having seven LGAs per senatorial zone. Presently, there are about 1000 health facilities (Private, Public, Mission) providing various levels of health care services in the state. There are 508 facilities that render Primary Health Care and 450 that render secondary health care in Anambra State. These are made up of Government hospitals including General hospital, Comprehensive health centers, health posts and primary health centers. There are also clinics, hospitals and maternities not owned by the government but by private, faith based organisations.

\section{Data collection}

Data was collected from the various LGA TB control registers in the state used for the study. Details collected include, name, age, sex, treatment unit/facility, date treatment started, treatment category, date of registration, site (pulmonary/extra pulmonary), TB smear results, $\mathrm{x}$-ray result (if applicable), HIV status and eventual treatment outcome. Some TB treatment cards were also reviewed with the LG TB registers to verify authenticity of the registers and for completeness of data collected.

Stratified sampling technique was used to conduct the study. A table of random numbers was used to select 2 LGAs each from the three senatorial zones in the state.

\section{Data analysis}

Data were analyzed with statistical package for social sciences version 15.0 (SPSS). Frequency tables, rates, ratio, proportion were used to review data. P value and Chi Square test were used to test statistical significance.

\section{Ethical consideration}

An official letter of request for access to official information from Anambra State Ministry of Health was written to the Commissioner of Health Anambra State; Director of Medical Services Anambra State Ministry of Health Awka and the State TBLCP Director. Patient's right to confidentiality was maintained during the study period

\section{Results}

Table 1. Socio demographic distribution of patients (Sex)

\begin{tabular}{|l|c|c|c|}
\hline \multirow{4}{*}{ Sex } & & Frequency & Percentage \\
\hline \multirow{3}{*}{} & Male & 563 & 57.4 \\
\cline { 2 - 4 } & Female & 417 & 42.6 \\
\cline { 2 - 4 } & Total & 980 & 100 \\
\hline
\end{tabular}

Table 1 show that a total of 980 TB patients registered for the study. The table also shows the distribution of patients by gender showing that, 563(57.4\%) were males and 417 (42.6\%) were females.

Table 2. TB Treatment Outcome

\begin{tabular}{|l|l|c|c|c|c|c|}
\hline $\begin{array}{l}\text { Treatment } \\
\text { Outcome }\end{array}$ & & Male & Female & Total & P value & $\begin{array}{c}\text { Chi } \\
\text { Square }\end{array}$ \\
\hline & Cured & $229(40.7 \%)$ & $210(50.4 \%)$ & $439(100 \%)$ & 0.063 & 3.434 \\
\hline & $\begin{array}{l}\text { Treatment } \\
\text { completed }\end{array}$ & $224(39.8 \%)$ & $147(35.3 \%)$ & $371(100 \%)$ & 0.330 & 0.949 \\
\hline & Died & $31(5.5 \%)$ & $22(5.3 \%)$ & $53(100 \%)$ & 0.8812 & 0.022 \\
\hline & Defaulter & $59(10.5 \%)$ & $27(6.5 \%)$ & $86(100 \%)$ & 0.0442 & 4.049 \\
\hline
\end{tabular}


Texila International Journal of Public Health

Volume 4, Issue 4, Dec 2016

\begin{tabular}{|l|l|c|c|c|c|c|}
\hline & $\begin{array}{l}\text { Transfer } \\
\text { out }\end{array}$ & $12(2.1 \%)$ & $4(1.0 \%)$ & $16(100 \%)$ & 0.1586 & 1.987 \\
\hline & Failure & $8(1.5 \%)$ & $7(1.6 \%)$ & $15(100 \%)$ & 0.749 & 0.102 \\
\hline & Total & $563(100 \%)$ & $417(100 \%)$ & $980(100 \%)$ & & \\
\hline
\end{tabular}

The table also showed that the treatment success rate (cure rate plus treatment completed rate) for the females is better than that for male patients (85.7\% vs. 80.5\%). Also males have higher default rate than females $(10.5 \%$ vs. $6.5 \%, \mathrm{p}=0.0442)$ showing significant association

Table 3. Prevalence of HIV Disease among TB patients

\begin{tabular}{|l|c|c|}
\hline HIV status & \multicolumn{2}{|c|}{ No of patients } \\
\hline HIV positive & 133 & $(27.7 \%)$ \\
\hline HIV negative & 348 & $(72.3 \%)$ \\
\hline Total & 481 & $(100 \%)$ \\
\hline
\end{tabular}

Table 3 showed that out of 481 TB patients that were screened for HIV, 133 (27.7\%) were HIV positive while 348 (72.3\%) were HIV negative. This puts the HIV prevalence rate of the study at $27.7 \%$.

Table 4. Socio demographic distribution of TB HIV patients (Gender)

\begin{tabular}{|l|l|c|c|c|c|}
\hline & & HIV positive & HIV negative & \multirow{2}{*}{$\mathrm{X}^{2}$} & \\
\cline { 1 - 1 } Variable & & $\mathrm{N}(\%)$ & $\mathrm{N}(\%)$ & & P -value \\
\hline & Male & $63(47.4 \%)$ & $217(62.4 \%)$ & & \\
\hline Sex & Female & $70(52.6 \%)$ & $131(37.6 \%)$ & 8.886 & 0.0029 \\
& & & & & \\
\hline & Total & $133(100 \%)$ & $348(100 \%)$ & & \\
\hline
\end{tabular}

Table 11 showed the effect of sex on HIV disease. The table showed that of the 133 HIV positive patients, 70 (52.6\%) were females compared to 63(47.4) who were males. There was also significant association between HIV disease and sex $(\mathrm{p}=0.0029)$

\section{Discussion}

TB programs in Nigeria aims amongst others to increase TB case notification while improving the treatment outcome.. This study reveals gender disparity in TB notification from people treated for TB in selected TB DOTS facility in the state. The study showed that out of 980 TB patients treated, 563 (57.4\%) patients were males while 417 (42.6\%) were females. This factor seen in other TB prevalence studies is of great economic importance as males are predominantly the family bread winners in Africa. Causes of increased male predominance include cultural seclusion practices, socialization patterns, and nutrition among the young females. The higher incidence of males amongst TB patients is consistent with other studies

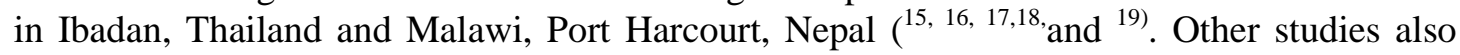
showed the effect of age in gender TB prevalence/notification as it was seen that increasing age is associated with increased male predominance in TB prevalence and notification $(22,23,24,25)$. However females have been reported to be more in number in TB treatment from other studies $\left({ }^{16,20,21}\right)$.

In low income countries like Nigeria low uptake of health care services especially by women can be attributed to differential access to health care services. Women often have fewer educational opportunities, lower income, reduced access to economic resources, poorer access to information, education and health invariably leading to lower socioeconomic status as compared with men. This means that many women are unable to locate and reach appropriate health services.[26]. In some cultural and religious settings, women are isolated 
and decisions about treatment including mobility, treatment uptake and related expenses are made by either the husband or family members ${ }^{\{27,28]}$. Furthermore, a comparison between ageand sex-specific prevalence and notification rates from 29 surveys in 14 countries suggested that the reasons for a low notification rate for TB in females was more due to epidemiological factors than a differential access of the health care. ${ }^{[27]}$ A higher proportion of women had minimal disease compared to men at the time of diagnosis, suggesting an earlier diagnosis among females. ${ }^{[29]}$

Furthermore, stigma attached to a positive TB diagnosis leads many women to forgo seeking necessary medical attention. This in some cases may lead to self medication, use of traditional and spiritual healers instead of using available DOTS centers to reduce being detected and affected stigma ${ }^{[30]}$ The male predominance for TB in the present study is consistent with data from other countries and could reflect occupational, behavioral, or immunological/biological contributions to risk ${ }^{[31,32,33]}$ Earlier studies have explained the role of cellular immunity in pathogenesis of $\mathrm{TB}^{[34]}$ Sex hormones, greater antibody production, and higher CD 4 count in women as compared with men have implication for better immune response in many earlier studies ${ }^{[35,36,37 .]}$ Other biological factors increasing male prevalence shows that men are biologically more vulnerable with more masked symptom than female (UNDP report) However females have been reported to be more in number in TB treatment from other studies ${ }^{16,20,21}$.

This study showed women having better TB treatment outcome than men. The female male cure rate is $50.4 \%$ vs $40.7 \%$ with a treatment success rate (cure plus treatment completed rates) of $85.7 . \%$ vs $80.5 \%$ ). Our study further showed that sex had a significant effect on default rate as male had a higher default rate than females $(10.5 \%$ vs $6.5 \%$, p value $=0.0442)$. This result is supported by a study done by Daniel and Oladapo in Sagamu which showed that male sex was a factor in default and that majority of TB patient defaulted at the continuation phase of the treatment probably due to the long duration of treatment and the feeling of being well during this period. That Women are less likely to die, default, or fail on treatment has been shown in the previous studies and this finding collaborates with the present study ${ }^{[38,39,40] \text {. }}$ Further suggestions have also showed that epidemiological factors are more responsible rather than differential access to the health care for these gender differences.

Of the 481 patients tested for HIV 133were positive giving a positivity rate of $27.7 \%$. In relation to gender, $34.8 \%$ (70/201) of the female patients tested positive while $22.5 \%$ (63/280) of the male patients tested positive for HIV infection. This difference was found to be statistically significant $(\mathrm{p}<0.05)$. This supports the fact that social inequalities, including gender and power relations, have an important impact on HIV transmission $\left({ }^{41)}\right.$. Recent reviews also suggest that women in many parts of the developing world are less likely to control how, when, and where sex takes place thereby increasing the likelihood of HIV infection ${ }^{(42) .}$ Although in their study of sex differences in the clinical presentation of urban Nigerian patients with pulmonary tuberculosis, Lawson and colleagues ${ }^{(43)}$ noted that women were more likely to be co-infected with HIV than males while Odaibo et al ${ }^{(44)}$ did not observe any significant difference in the rate of co-infection in relation to gender

\section{Conclusion}

Our study demonstrates a sex difference in the TB notification, default and TB HIV coinfection rates. This difference, traditionally attributed to poor access to health care in females, is at least partially due to biological reasons. Better treatment outcomes in females may reflect biological differences in addition to health system-related factors. Integrated research is necessary to outline the relative roles played by biological factors and gender issues in causing these differences in the notification rates and treatment outcomes of patients under the RNTCP. 
Texila International Journal of Public Health

Volume 4, Issue 4, Dec 2016

\section{Limitations}

There are some limitations with the study. The retrospective nature of the study made it impossible to evaluate the contributions of other factors that can impact on sex and treatment outcome. Also the Are was limitation on the information collected on the characteristics of patients in the program from TB treatment card and LG TB registers used by NTBLCP.

\section{References}

[1] Akinola A F, Abimbola S O, Afolabi E B. Treatment outcomes among pulmonary tuberculosis patients at treatment centers in Ibadan, Nigeria. Annals of African medicine, 2009; 8 (2): 100-104.

[2] Aggleton P, Rivers K. Gender Inequalities in Health and Diseases. Int Gender Iss 2007:28 - 32.

[3] Bello S I. Challenges of DOTS implementation strategy in the treatment of tuberculosis in a tertiary health institution, Ilorin, Nigeria. African journal of pharmacy and pharmacology, $2010 ; 4$ (4): 158- 164.

[4] Borgdorff MW, Nagelkerke NJ, Dye C, Nunn P. Gender and tuberculosis: A comparison of prevalence surveys with notification data to explore sex differences in case detection. Int J Tuberc Lung Dis. 2000;4:123-32. [PubMed]

[5] Belay T, Abebe M, Assengedegh B, Dieter R, Frank E, Ulrich S. Treatment outcome of TB patients at Gondar university teaching hospital, North West Ethiopia. BMC Public Health 2009; 9:37.

[6] Central TB Division, Directorate General of Health Services, Ministry of Health and Family Welfare, Nirman Bhawan, New Delhi. TB India 2012. RNTCP Status Report. 2012:7-17.]

[7] D. Chan-Yeung M, Noertjojo K, Chan SL, Tam CM. Sex differences in tuberculosis in Hong Kong. Int J Tuberc Lung Dis 2002;6:11-8.

[8] Diwan VK, Thorson A. Sex, gender, and tuberculosis. Lancet. 1999;353:1000-1. [PubMed]

[9] Frank-Peterside N, Onwuka A P, Okonko I O. Epidemiology of Pulmonary Tuberculosis in University of PortHarcourt Teaching Hospital: age related disparities. Science pub.net/report; 2012, 4(5).

[10] Glynn J, Sonnenberg P, Nelson G, Bester A, Shearer S, Murray J. Increasing risk of TB with increasing duration of HIV infection: results from 2000 men followed for 12 years. International journal for TB and lung disease, 2007; 11 (11):112.

[11] Gidado M, Ejembi C L. Tuberculosis case management and treatment outcome: Assessment of the effectiveness of public private mix of tuberculosis programme in Kaduna state, Nigeria. Annals of African medicine.2009; 8 (1): 25-31.

[12] G = Karim F, Islam MA, Chowdhury AM, Johansson E, Diwan VK. Gender differences in delays in diagnosis and treatment of tuberculosis. Health Policy Plan. 2007;22:329-34. [PubMed]

[13] $\mathrm{H}=$ Holmes CB, Hausler H, Nunn P. A review of sex differences in the epidemiology of tuberculosis. Int J Tuberc Lung Dis. 1998;2:96-104. [PubMed]

[14] Hawkes S, Buse K. Gender and global health: evidence, policy, and inconvenient truths. Lancet. 2013; 381:1783-1787. doi: 10.1016/S0140-6736(13)60253-6 PMID: 23683645

[15] Holmes CB, Hausler H, Nunn P. A review of sex differences in the epidemiology of tuberculosis. Int J Tuberc Lung Dis. 1998;2:96-104.]

[16] K.= Yamasaki-Nakagawa M, Ozasa K, Yamada N, Osuga K, Shimouchi A, Ishikawa N, et al. Gender difference in delays to diagnosis and health care seeking behaviour in a rural area of Nepal. Int J Tuberc Lung Dis. 2001;5:24-31. [PubMed]

[17] Karim F, Islam MA, Chowdhury AM, Johansson E, Diwan VK. Gender differences in delays in diagnosis and treatment of tuberculosis. Health Policy Plan. 2007;22:329-34. [PubMed]

[18] Khatri GR, Frieden TR. The status and prospectus of tuberculosis control in India. Int J Tuberc Lung Dis 2000;4:193-200. ]

[19] L=. Begum V, de Colombani P, Das Gupta S, Salim AH, Hussain H, Pietroni M, et al. Tuberculosis and patient gender in Bangladesh: Sex differences in diagnosis and treatment outcome. Int J Tubercu Lung Dis. 2001;5:604-10. [PubMed]

[20] Long NH, Johansson E, Diwan VK, Winkvist A. Fear and social isolation as consequences of tuberculosis in Vietnam: A gender analysis. Health Policy. 2001;58:69-81. [PubMed]

[21] Long NH, Johansson E, Diwan VK, Winkvist A. Fear and social isolation as consequences of 
tuberculosis in Vietnam: A gender analysis. Health Policy. 2001;58:69-81. [PubMed]

[22] Lawson L, Lawson JO, Olajide I, Ememyonu N, Bello CS, Olatunji OO, Davies PD, Thacher TC. Sex differences in the clinical presentation of urban Nigerian patients with pulmonary tuberculosis. West Afr J Med. 2008 Apr;27(2):82-6. [PubMed]]

[23] Lagrada L P, Uehara N, Kawahara K. Analysis of factors of treatment completion in DOTS health facilities in Metro Manilla Phillipines, a case control study. PMID,2008 ; 83(12):765 -772.

[24] Long, N.H., E. Johansson, V.K. Diwan and A. Winkvist, Fear and social isolation as consequences of tuberculosis in Vietnam: a gender analysis, Health Policy 2001, 58(1):69-81.

[25] M= Raja A. Immunology of tuberculosis. Indian J Med Res. 2004;120:213-32. [PubMed]

[26] Mark J R. Chronic cough due to tuberculosis and other infections. ACCP evidence based clinical practice, 2006; 129; 1975 -2015.

[27] Mukherjee A, Saha I, Sarkar A, Chowdhury R. Gender differences in notification rates, clinical forms and treatment outcomes of tuberculosis patients placed under RNTCP. Lung India. 2012;29:1202. [PMC free article] [PubMed]

[28] Mukherjee A, Saha I, Sarkar A, Chowdhury R. Gender differences in notification rates, clinical forms and treatment outcomes of tuberculosis patients placed under RNTCP. Lung India. 2012;29:120-

2. [PMC free article] [PubMed]

[29] Martinez HZ, Suazo FM, Gil JQC, Bello CG, Escalera AMA, Marquez HG, Casanova LG. Spatial epidemiology of bovine tuberculosis in Mexico. Veterinaria Italiana. 2007;43(3):629-63. [PubMed]

[30] N= Ahmed J, Chadha VK, Singh S, Venkatachalappa B, Kumar P. Utilization of RNTCP services in rural areas of Bellary District, Karnataka, by gender, age and distance from health centre. Indian $\mathrm{J}$ Tuberc. 2009;56:62-8. [PubMed]

[31] Nigerian Stop TB Partnership Strategic Plan 2011

[32] Nigeria National Census :2006

[33] $\mathrm{O}=$. Yang ZH, Kong Y, Wilson F, Foxman B, Fowler AH, Marrs CF, et al. Identification of risk factors for extra pulmonary tuberculosis. Clin Infect Dis. 2004;38:199-205. [PubMed]

[34] Odaibo GN, Gboun MF, Ekanem EE, Gwarzo SN, Saliu I, Egbewunmi SA, Abebe EA, Olaleye DO. HIV infection among patients with PTB in Nigeria. African Journal of Medicine and Medical Sciences. 2006;35:93-98. [PubMed]]

[35] Onifade, D.A. et al., Gender-related factors influencing tuberculosis control in shantytowns: a qualitative study, BMC Public Health 2010, 10:381, http://www.biomedcentral.com/1471-2458/10/381. [36] $\mathrm{P}=$. Martinez AN, Rhee JT, Small PM, Behr MA. Sex differences in the epidemiology of tuberculosis in San Francisco. Int J Tuberc Lung Dis. 2000;4:26-31. [PubMed

[37] Sweet H, Denison S. Gender inequalities in health and diseases. Int Gender Iss 2008: 5-32.

[38] World Health Organization, Global TB Report, Geneva;2015.

[39] WHO - Africa Region. Strategic plan for tuberculosis control for the African region: 2006 - 2010. WHO report - AFRO report 2006. Harare, Zimbabwe: World Health Organisation - Regional Office for Africa, 2006).

[40] World Health Organisation, Global TB Report, Geneva;2014.

[41] Waisbord, S., Behavioral Barriers in Tuberculosis Control: A Literature Review, The CHANGE Project/Academy for Educational Development, Washington, DC, 2005, http://pdf.usaid.gov/pdf_docs/Pnadf406.pdf.

[42] United Nations General Assembly. United Nations millennium declaration. A/RES/55/2. 2000 Sep 8 [cited 2 Aug 2016]. Available: http://www.un.org/millennium/declaration/ares552e.htm.

[43] Yamasaki-Nakagawa M, Ozasa K, Yamada N, Osuga K, Shimouchi A, Ishikawa N, et al. Gender difference in delays to diagnosis and health care seeking behaviour in a rural area of Nepal. Int $\mathrm{J}$ Tuberc Lung Dis. 2001;5:24-31. [PubMed]

[44] Zachariah R, Fitzgerald M, Massaquoi M, Acabu A, Chiloma D, Salaniponi F M L, Harries A D. Does antiretroviral treatment reduce case fatality among HIV positive patients with Tuberculosis in Malawi. International journal for TB and lung disease, 2007; 11 (8):848 -853. 